OPEN ACCESS

Edited by:

Jesus De La Fuente,

University of Almería, Spain

Reviewed by:

Dejan Stevanovic,

General Hospital Sombor, Serbia Melissa Christine Davis,

Curtin University, Australia

*Correspondence:

Carolina Gonzálvez carolina.gonzalvez@ua.es

Specialty section:

This article was submitted to Educational Psychology, a section of the journal Frontiers in Psychology

Received: 30 September 2016 Accepted: 12 December 2016 Published: 26 December 2016

Citation:

Gonzálvez C, Inglés CJ, Kearney CA,

Vicent M, Sanmartín Rand García-Fernández JM (2016) School Refusal Assessment Scale-Revised: Factorial Invariance and Latent Means Differences across Gender and Age in Spanish Children.

Front. Psychol. 7:2011. doi: 10.3389/fpsyg.2016.02011

\section{School Refusal Assessment Scale-Revised: Factorial Invariance and Latent Means Differences across Gender and Age in Spanish Children}

\author{
Carolina Gonzálvez ${ }^{1 *}$, Cándido J. Inglés ${ }^{2}$, Christopher A. Kearney³ ${ }^{3}$ Maria Vicent ${ }^{1}$, \\ Ricardo Sanmartín ${ }^{1}$ and José M. García-Fernández'1
}

${ }^{1}$ Department of Developmental and Psychology and Didactics, University of Alicante, Alicante, Spain, ${ }^{2}$ Department of Health Psychology, Miguel Hernandez University of Elche, Elche, Spain, ${ }^{3}$ Department of Psychology, University of Nevada, Las

Vegas, Las Vegas, NV, USA

The aim of this study was to analyze the factorial invariance and latent means differences of the Spanish version of the School Refusal Assessment Scale-Revised for Children (SRAS-R-C) in a sample of 1,078 students (50.8\% boys) aged $8-11$ years $(M=9.63$, $S D=1.12$ ). The results revealed that the proposed model in this study, with a structure of 18 items divided into four factors (Negative Affective, Social Aversion and/or Evaluation, To Pursue Attention and Tangible Reinforcements), was the bestfit model with a tetra-factorial structure, remaining invariant across gender and age. Analysis of latent means differences indicated that boys and 11-year-old students scored highest on the Tangible Reinforcements subscale compared with their 8- and 9year-old peers. On the contrary, for the subscales of Social Aversion and/or Evaluation and to Pursue Attention, the differences were significant and higher in younger age groups compared to 11-year-olds. Appropriate indexes of reliability were obtained for SRAS-R-C subscales $(0.70,0.79,0.87$, and 0.72$)$. Finally, the founded correlation coefficients of scores of the SRAS-R-C revealed a predictable pattern between school refusal and positive/negative affect and optimism/pessimism.

Keywords: school refusal, validation, factorial invariance, latent means differences, primary education, SRAS-R-C

\section{INTRODUCTION}

Regular class attendance is a key factor for better academic results (Yahaya et al., 2010; Thornton et al., 2013), development of social skills and conflict-resolution strategies (Kearney and Graczyk, 2014), and prevention of substance use and behavioral problems in youth (Maynard et al., 2012; Guller et al., 2015; Dembo et al., 2016; Thrul et al., 2016). School refusal, however, affects as many as $28-35 \%$ of students if the causal heterogeneity behind this behavior is considered (e.g., anxiety, pursuit of other interests outside of school hours; Mihalas, 2014). Furthermore, 28\% of students in Spain have presented unjustified absences from an educational institution (Organisation for Economic Co-operation and Development, 2012). School refusal tends to affect youths aged 1013 years, but less strong effects have been noted for gender or ethnicity (Pina et al., 2009). School refusal behavior refers to a child's refusal to go to school and/or persistent difficulty remaining in class for an entire school day, and this behavior may or may not be based on anxiety 
(Hendron and Kearney, 2011). Despite high prevalence rates and the adverse consequences linked to this problem, there are limited available instruments to specifically assess this construct, especially for Spanish students (Inglés et al., 2015; García-Fernández et al., 2016). At the international level, the School Refusal Assessment Scale for Children-Revised (SRAS-RC; Kearney, 2002a) is the most commonly used assessment scale, and it is mainly applied in American (Kearney, 2016), French (Brandibas et al., 2001, 2004), German (Hochadel et al., 2014), Korean (Kim, 2010), English (Richards and Hadwin, 2011), and Turkish (Seçer, 2014) populations. Other instruments to evaluate school refusal have been proposed to assess this construct, such as the scale Feelings of School Avoidance (Watanabe and Koishi, 2000), School Avoidance Scale (Fujigaki, 1996), and School Refusal Personality Scale (Honjo et al., 2003). However, these instruments have not been sufficiently validated.

The aim of the SRAS-R-C is to identify the four functions underlying problematic school refusal behavior: (I) To Avoid School Related Stimuli that Provoke a Sense of General Negative Affectivity, (II) To Escape from Aversive Social and/or Evaluative Situations at School, (III) To Pursue Attention from Significant Others, and (IV) To Pursue Tangible Reinforcement Outside the School Setting. After the publication of the original test (SRAS; Kearney and Silverman, 1993), several studies focused their analyses in assessing the psychometric properties of the instrument, both the initial version (Brandibas et al., 2001; Higa et al., 2002; Kim, 2010) and the revised version (Kearney, 2006; Lyon, 2010; Haight et al., 2011; Richards and Hadwin, 2011; Seçer, 2014).

To improve the psychometric quality of the original version, Kearney (2002a) revised the scale with a diverse sample of 168 youth with school refusal behavior aged 6-17 years $(M 1=13.9$, $D E=1.9 ; M 2=11.9, D E=2.8)$. Results indicated adequate concurrent validity with the original version of the scale and significant scores for each of the four factors $(M=0.68)$. In addition, higher average scores in fear and trait anxiety were found in students whose school refusal was maintained by negative reinforcement. On the other hand, students whose school refusal was maintained by tangible positive reinforcement outside of the school scored higher in externalizing behaviors.

Kearney (2006) attempted to clarify and statistically determine which functional model (2, 3, or 4 factors) better adjusted with the SRAS-R-C (Kearney, 2002a). A confirmatory factor analysis (CFA) in a sample of 213 US children and adolescents with school refusal behavior aged 6-16 years revealed that none of the models met criteria for goodness-of-fit. After two items were removed from Factor IV (20 and 24), the four factor model did meet criteria for goodness-of-fit. Test-retest reliability coefficients over a period of 1-2 weeks were acceptable for each of the four factors $(0.64,0.73,0.78,0.56)$.

In addition, Lyon (2010) and Haight et al. (2011) significantly confirmed the structure of four factors with CFAs, reaching a better adjustment of the model after removing some items. On the one hand, in Lyon's (2010) study with a community sample of 174 students aged 10-12 years, items 16, 20, and 24 were eliminated from the fourth factor. On the other hand, Haight et al. (2011) removed item 19 from the third factor and item
20 from the fourth factor with a sample of 216 students aged 11-17 years with primary school refusal behavior. Richards and Hadwin (2011) evaluated the factorial structure of the SRASR-C through a CFA in a community sample of 152 students aged 12-13 years. Factor IV was completely removed and a three factor structure was supported. Seçer (2014) conducted the most recent validation of the SRAS-R-C in a sample of 480 Turkish adolescents aged 13-18 years who did not refuse to go to school. This study supported the four factor structure with test-retest reliability values over a 2 -week period of 0.86 , and it provided a version of 19 items with the best adjustment after removing items $4,17,18,19$, and 20. Additional research is thus needed regarding the factorial structure of the SRAS-R-C, especially in Spanish students. There are studies that have used this scale with children aged between 5 and 9 years (Kearney et al., 2005) and 811 years (Hochadel et al., 2014). However, there are not previous validations of the SRAS-R-C with pre-adolescents, whereas there are different validations of this scale only with adolescents (Lyon, 2010; Haight et al., 2011). Consequently, a pre-adolescent sample participated in this study in order to avoid analyzing this behavior in a wide age range covering late childhood and adolescence. The aim of this study was to validate the SRAS-R-C in a representative sample of Spanish students aged 8-11 years. This general aim can be specified in the following statements: (1) To examine the factorial invariance of the SRAS-R-C across gender and age groups; (2) To analyze the latent means differences across gender and age; (3) To examine the correlations between school refusal and positive/negative affectivity and optimism/pessimism.

\section{MATERIALS AND METHODS}

\section{Ethics Statement}

This research was reviewed and approved by the DirectorateGeneral of Scientific and Technological Research-Ministry of Economy and Competitiveness (Spain) (EDU2012-35124) and according to the standards established by the Ethics Committee of the University of Alicante and the University Miguel Hernandez.

\section{Participants}

The initial sample of this study comprised 1416 students recruited by random cluster sampling in four Spanish provinces (Alicante, Albacete, Murcia, and Sevilla). Four school centers were selected from each province. As a result, 16 school centers were selected, which are disaggregated in 12 public centers, two state-funded schools and two private schools, located in urban and rural zones. Once the school centers were determined, a class for each academic year was randomly selected (four classes per center), and on average each school contributed 89 participants. From the initial sample, 182 students (12.85\%) were excluded because they did not obtain paternal consent to participate in the research, 108 $(7.63 \%)$ because of omissions and mistakes in their answers, and $48(3.39 \%)$ due to the fact that they were non-Spanish students. The final sample included 1078 participants, 548 boys and 530 girls (50.8 and $49.2 \%$, respectively), aged $8-12$ years $(M=9.63$; 
$S D=1.12)$. No statistically significant differences between the four groups were found with respect to gender and academic year.

\section{Measures}

The School Refusal Assessment Scale Revised for Children (SRAS-R-C; Kearney, 2002a) is the validated instrument in this study and it is a scale with good psychometric properties that were presented earlier.

The Positive and Negative Affect Schedule for Children (10-Item PANAS-C; Ebesutani et al., 2012) is a 10-item selfreport measure of positive and negative affect in children and young people aged 6-18 years. The subscales have demonstrated appropriate rates of internal consistency ( 0.86 positive affect and 0.82 negative affect; Ebesutani et al., 2012). Both subscales were used for this study and the coefficients of internal consistency (Cronbach's alpha) were 0.75 for the positive affect and 0.76 for the negative affect.

The Youth Life Orientation Test (YLOT; Ey et al., 2005) is a 16-item measure of positive expectations (optimism) and negative expectations (pessimism). The subscales have demonstrated an acceptable range for internal consistency and have shown high 1-month test-retest reliability $(0.68$ for optimism and pessimism; Ey et al., 2005). Convergent and discriminant validity were demonstrated via association with other measures of hope and self-efficacy. Both subscales were used in this study and the coefficients of internal consistency (Cronbach's alpha) were 0.79 for optimism and 0.78 for pessimism.

The same translation process was conducted for the three scales used in this study (Hambleton and Lee, 2015). First, the items in the original versions in English were translated to Spanish by a native expert in educational psychology and with university studies in English translation. Once the translation was finished, a native English speaker with Spanish knowledge and an expert in psychology performed the back-translation to the original language. Finally, we evaluated and compared again the adapted version by a group of judges-experts endorsing proper translation.

\section{Procedure}

To start, a meeting with the principals and the education center management team was held to expose the objectives of this research work and the evaluation instruments used, to ask for their permission, and to achieve their collaboration. Afterward, an informative letter was written to inform the students' parents about the purpose of this study and to ask for their written consent to allow their children to participate in the research activity.

The measuring instruments were administered to the whole class as a collective and its completion was voluntary, assigning a key to the test battery for each of the participants. During the fulfillment of the questionnaires, the researcher was there to solve doubts, and the tutor of the different academic years also provided assistance. Each of the classes was composed by 20 students and one session of $50 \mathrm{~min}$ was used to complete the tests (15-20 min the SRAS-R-C, 5-10 min the PANAS-C, and 10-15 min the YLOT).

\section{Statistical Analyses}

To examine the different proposed model for the SRAS-R-C, nine confirmatory factor analyses (CFA) were conducted over nine alternative proposals based on previous research and an own model designed in this investigation. The polychoric correlation matrix was analyzed using weighted least squares (WLS) to confirm the parameters of the different models. It was confirmed that there was no multivariate normality. Thus, the Mardia's coefficient was 93.43 because a value of five points is considered as the limit for a multivariate normal distribution (Bentler, 2005). Therefore, the Satorra-Bentler scaled $\chi^{2}\left(\mathrm{~S}-\mathrm{B} \chi^{2}\right)$ was used. In addition, different goodness of fit indices were applied to verify the adequacy of the models on the factor structure of the SRASR-C. The next goodness-of-fit indexes were calculated: the Robust Root Mean Square Error of Approximation (R-RMSEA: $<0.08$ acceptable and $<0.06$ excellent), the Standardized Root Mean Square Residual (SRMR: close to 0.08 acceptable and $<0.05$ good fit), the Robust Comparative Fit Index (R-CFI: $\geq 0.90$ acceptable and $>0.95$ good fit), and the Tucker Lewis Index (TLI: $\geq 0.90$ acceptable; Hu and Bentler, 1999; Brown, 2006). In addition, a classic item analysis was performed and the reliability of the scale and its factors were checked by Cronbach's alpha coefficient, whose $\alpha$ values were considered acceptable at $\geq 0.70$.

To examine the factor invariance of the SRAS-R-C, for the four factor model proposed in this study, a multigroup CFA was performed to check the invariance of the measurement and structure through groups of gender and age. To do this, several hierarchical steps were followed based on the existing literature (Byrne, 2008a,b; Liu et al., 2015; Samuel et al., 2015). To check the good fit of the models, the goodness-of-fit indexes explained before were used (R-RMSEA, SRMR, R-CFI, and TLI) along with the criteria of invariance: $\Delta$ CFI $(\Delta \mathrm{CFI}<0.01$; Cheung and Rensvold, 2002) and the level of non-significant probability associated to the $\Delta \mathrm{S}-\mathrm{B} \chi^{2}$ (Dimitrov, 2010). Finally, the latent means difference across gender and age were performed by the Critical Ratio (CR), considering that with results $>1.96$ or $<-1.96$ the estimation of equality is rejected (Tsaousis and Kazi, 2013). Besides, effect sizes were measured using Cohen's $d$ (Fritz et al., 2012). Regarding the gender, the group of girls was set to zero to develop its comparison with the boys. About the age, each group was successively set to zero to establish the comparative with other groups freely estimated.

The correlations between the different factors of the SRASR-C were obtained by Pearson product-moment correlation coefficient, as well as its discriminant validity from measures that evaluate the affect and optimism/pessimism. The interpretation of these results was performed according to the criteria proposed by Cohen (1988) about the magnitude of the effect sizes. Statistical analyzes were calculated using SPSS 20 and EQS 6.1 statistical programs.

\section{RESULTS}

\section{Confirmatory Factor Analyses}

Data regarding the CFAs are in Table 1. Six of the tested models supported the four factor structure (Models 4a, 4b, 4c, 4cII, 4d, 
TABLE 1 | Confirmatory factor analyses: goodness-of-fit indices of the statistic models of the School Refusal Assessment Scale-Revised for Children (SRAS-R-C).

\begin{tabular}{|c|c|c|c|c|c|c|}
\hline & S-B $\chi^{2}$ & $d f$ & R-RMSEA $90 \% \mathrm{Cl}$ & SRMR & R-CFI & TLI \\
\hline Model 3a & 1560.95 & 249 & 0.070 [0.067-0.073] & 0.087 & 0.675 & 0.640 \\
\hline Model 3b & 237.67 & 51 & 0.040 [0.032-0.048] & 0.045 & 0.931 & 0.911 \\
\hline Model 4a & 1261.53 & 246 & 0.062 [0.058-0.065] & 0.074 & 0.748 & 0.718 \\
\hline Model 4b & 676.85 & 183 & $0.050[0.046-0.054]$ & 0.073 & 0.841 & 0.818 \\
\hline Model 4c & 692.28 & 183 & 0.051 [0.047-0.055] & 0.059 & 0.839 & 0.816 \\
\hline Model 4cll & 530.63 & 182 & 0.042 [0.038-0.046] & 0.053 & 0.890 & 0.873 \\
\hline Model 4d & 1015.83 & 203 & $0.061[0.057-0.065]$ & 0.073 & 0.767 & 0.735 \\
\hline Model $4 \mathrm{e}$ & 482.36 & 146 & 0.046 [0.042-0.051] & 0.055 & 0.877 & 0.856 \\
\hline Own model & 341.7284 & 129 & $0.039[0.034-0.044]$ & 0.050 & 0.917 & 0.901 \\
\hline
\end{tabular}

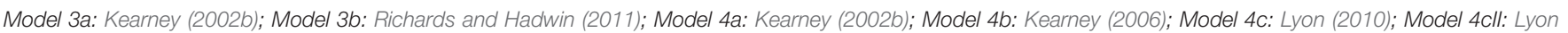

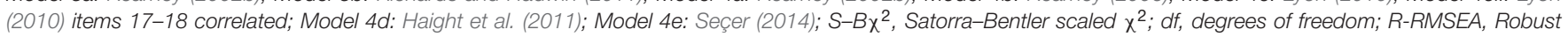

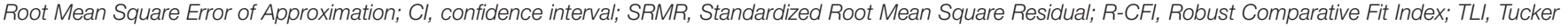
Lewis Index. $p<0.001$ for $S-B \chi^{2}$ in all cases.

and $4 \mathrm{e}$ ), whereas the remaining two models showed a better adjustment with a three factor structure (Models $3 \mathrm{a}$ and $3 \mathrm{~b}$ ). Model 3b with 12 items was the model with the best-fit indices. However, if four factor models are considered, then the model proposed by the research group showed the best goodness-offit indices. As a result, a final four factor structure formed by 18 items is proposed for the Spanish version of the SRAS-R-C: Factor I. Avoid School Related Stimuli that Provoke Negative Affectivity (1, 5, 9, 13, 21), Factor II. Escape Aversive Social and/or Evaluative Situations at School (2, 6, 10, 14, 22), Factor III. Pursue Attention from Significant Others (3, 7, 11, 15, 23), and Factor IV. Pursue Tangible Reinforcement Outside the School Setting $(4,8,12)$.

Cronbach reliability coefficients for each of the four factors were 0.70 (I. Avoid School Related Stimuli that Provoke Negative Affectivity), 0.79 (II. Escape Aversive Social and/or Evaluative Situations at School), 0.87 (III. Pursue Attention from Significant Others), and 0.72 (IV. Pursue Tangible Reinforcement Outside the School Setting). The 2-week test-retest reliability ranged from 0.70 (IV. Pursue Tangible Reinforcement Outside the School Setting) to 0.75 (II. Escape Aversive Social and/or Evaluative Situations at School).

\section{Classical Item Analysis}

Item means ranged from 4.53 (item 8) to 0.41 (item 6) and the standard deviation ranged from 2.21 (item 23) to 1.06 (item $6)$. The item-scale correlation coefficients for the four factors ranged from 0.63 (III. Pursue Attention from Significant Others. Items: 2, 6, and 22) to 0.81 (IV. Pursue Tangible Reinforcement Outside the School Setting. Item: 12). Internal consistency of the items with one item removed ranged from 0.75 (III. Pursue Attention from Significant Others. Item: 11) to 0.79 (IV. Pursue Tangible Reinforcement Outside the School Setting. Item: 8).

\section{Factorial Invariance across Gender and Age for the SRAS-R-C}

Results regarding measurement and structural invariance across gender and age are in Tables 2 and 3, respectively. A stepwise hierarchical method was applied to analyze the invariance of the SRAS-R-C in which restrictions were imposed on the obtained model. First, a baseline model (Model 0) with no equality constraints across gender or age showed adequate goodness-of-fit indices (TLI and R-CFI $>0.90$; R-RMSEA $<0.05$; SRMR $<0.08$; $\Delta \mathrm{CFI}<0.01)$. All factor loadings were then constrained to be equal across gender and age groups to calculate the metric invariance (Model 1). The goodness-of-fit indices for this model were also reasonable. Subsequently, constraints were set on the intercepts of the variables and a new model was created (Model 2), which showed adequate goodness-of-fit indices. Then, to establish measurement invariance, strict invariance (Model 3) set the factor loadings, the intercepts of the variables, and the variances and covariances of the errors. This model also showed reasonable goodness-of-fit indices. Finally, the structural invariance (Model 4) consisted of setting the variances of the factors and equalizing their covariances in Model 2. The goodness-of-fit indices of this nested model also were adequate. Moreover, the Satorra-Bentler scaled $\chi^{2}$ was used in all the tested models (Models 1, 2, 3, and 4) in gender and age. All $\Delta \mathrm{S}-\mathrm{B} \chi^{2}$ of the tested models showed no statistically significant differences $(p>0.05)$, so the measurement and structural invariance of the SRAS-R-C were confirmed across gender and age.

\section{Latent Means Differences across Gender and Age on the SRAS-R-C}

The model for comparing gender groups used girls as the reference group. Given that there were four age groups $(8,9,10$, and 11 years), three reference models were established to make all possible comparisons. In each model, the lowest age group was set to zero: Model $1=8$ versus 9-, 10-, and 11-year-olds; Model $2=9$ - versus 10 - and 11-year-olds; and Model $3=10$ - versus 11-yearolds. For gender groups, the fit statistics of the latent mean structures were reasonable $\left(\chi^{2}=678.23, d f=286\right.$, $p<0.000$, R-CFI $=0.906$, R-RMSEA $=0.036$, CI $=0.033-$ 0.040 , and SRMR $=0.054)$. Fit statistics of the latent mean structures for the age groups were reasonable in all 
TABLE 2 | Goodness-of-fit indices for the own model of the SRAS-R-C depending on gender.

\begin{tabular}{|c|c|c|c|c|c|c|c|c|c|}
\hline & $x^{2}$ & S-B $x^{2}$ & $d f$ & TLI & R-CFI & R-RMSEA & SRMR & $\Delta S-B \chi^{2}(\Delta d f, p)$ & $\Delta \mathrm{CFI}$ \\
\hline Boys & 348.54 & 256.65 & 129 & 0.901 & 0.915 & 0.042 [0.035-0.050] & 0.051 & & \\
\hline Girls & 301.28 & 217.77 & 129 & 0.920 & 0.934 & $0.036[0.028-0.044]$ & 0.052 & & \\
\hline Model 0 & 649.82 & 474.06 & 258 & 0.910 & 0.924 & 0.028 [0.024-0.032] & 0.052 & & \\
\hline Model 1 & 667.53 & 482.23 & 272 & 0.918 & 0.926 & $0.027[0.023-0.031]$ & 0.054 & $10.84(14,0.698)$ & 0.002 \\
\hline Model 2 & 684.90 & 500.99 & 290 & 0.913 & 0.925 & 0.027 [0.023-0.030] & 0.054 & $15.69(18,0.614)$ & -0.001 \\
\hline Model 3 & 717.86 & 505.91 & 308 & 0.917 & 0.928 & 0.025 [0.022-0.029] & 0.055 & $14.63(18,0.687)$ & 0.003 \\
\hline Model 4 & 697.23 & 507.02 & 300 & 0.918 & 0.927 & 0.026 [0.022-0.030] & 0.057 & $7.66(10,0.662)$ & 0.002 \\
\hline
\end{tabular}

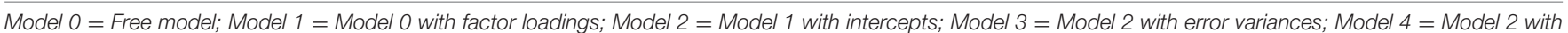

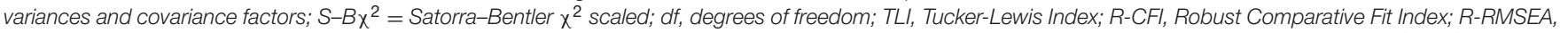

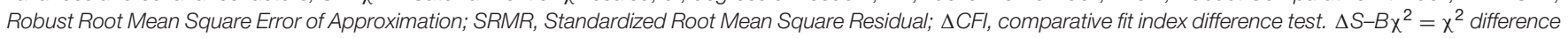
model comparison test; $\Delta d f$, difference between degrees of freedom.

TABLE 3 | Goodness-of-fit indices for the own model of the SRAS-R-C depending on age.

\begin{tabular}{|c|c|c|c|c|c|c|c|c|c|}
\hline & $x^{2}$ & S-B $\chi^{2}$ & $d f$ & TLI & R-CFI & R-RMSEA & SRMR & $\Delta \mathrm{S}-\mathrm{B} \chi^{2}(\Delta \mathrm{df}, p)$ & $\Delta \mathrm{CFI}$ \\
\hline 8 year old & 195.72 & 157.38 & 129 & 0.933 & 0.943 & $0.032[0.005-0.047]$ & 0.058 & & \\
\hline 9 year old & 207.11 & 147.29 & 129 & 0.967 & 0.972 & $0.022[0.000-0.038]$ & 0.058 & & \\
\hline 10 year old & 257.82 & 192.28 & 129 & 0.920 & 0.934 & $0.044[0.031-0.057]$ & 0.060 & & \\
\hline 11 year old & 294.35 & 222.70 & 129 & 0.900 & 0.918 & $0.054[0.042-0.066]$ & 0.066 & & \\
\hline Model 0 & 954.99 & 719.11 & 516 & 0.930 & 0.942 & $0.020[0.016-0.023]$ & 0.060 & & \\
\hline Model 1 & 1046.73 & 767.81 & 558 & 0.925 & 0.939 & 0.019 [0.016-0.023] & 0.069 & $51.05(42,0.160)$ & -0.003 \\
\hline Model 2 & 1095.61 & 820.35 & 612 & 0.914 & 0.934 & 0.019 [0.015-0.022] & 0.069 & $46.63(54,0.751)$ & -0.005 \\
\hline Model 3 & 1251.24 & 874.49 & 666 & 0.911 & 0.932 & 0.019 [0.015-0.022] & 0.072 & $61.98(54,0.213)$ & -0.002 \\
\hline Model 4 & 1178.33 & 849.16 & 642 & 0.916 & 0.932 & 0.019 [0.015-0.022] & 0.079 & $33.76(30,0.291)$ & -0.002 \\
\hline
\end{tabular}

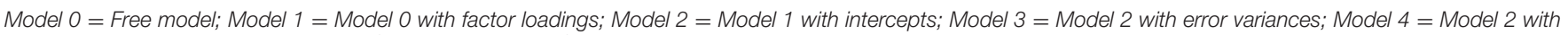
variances and covariance factors; $S-B \chi^{2}$, Satorra-Bentler $\chi^{2}$ scaled; df, degrees of freedom; TLI, Tucker-Lewis Index; R-CFI, Robust Comparative Fit Index; R-RMSEA,

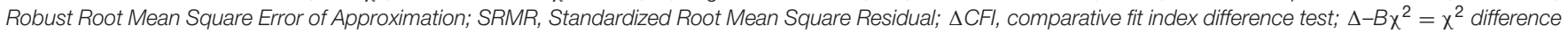
model comparison test; $\Delta d f$, difference between degrees of freedom.

cases (Model 1: $\chi^{2}=1078.24, ? d f=600, p<0.000$, $\mathrm{R}-\mathrm{CFI}=0.917, \mathrm{R}-\mathrm{RMSEA}=0.029, \mathrm{CI}=0.026-0.032$, and SRMR $=0.072$; Model 2: $\chi^{2}=837.93, d f=495, p<0.000$, $\mathrm{R}-\mathrm{CFI}=0.915$, R-RMSEA $=0.035, \mathrm{CI}=0.031-0.038$, and SRMR $=0.072$; Model 3: $\chi^{2}=608.44, d f=286, p<0.000$, $\mathrm{R}-\mathrm{CFI}=0.906, \mathrm{R}-\mathrm{RMSEA}=0.048, \mathrm{CI}=0.043-0.053$, and SRMR $=0.074)$.

The structured mean differences across gender and age groups are in Table 4. With regard to gender, no statistically significant differences were found except for Factor IV (Pursue Tangible Reinforcement Outside the School Setting), in which boys had significantly higher structured means than girls with a small size effect size $(d=0.13)$. With respect to age groups, 11year-olds had significantly higher means in Factor IV than 8$(d=2.13)$ and 9 -year-olds $(d=2.07)$. However, 11-year-olds had significantly lower means in the second factor (To Escape Aversive Social and/or Evaluative Situations at School) than 8 -year-olds $(d=-0.19)$ and in the third factor (To Pursue Attention from Significant Others) than 8- $(d=-0.37)$, 9$(d=-0.27)$, and 10-year olds $(d=-0.38)$. The effect sizes were small except for the fourth factor that presented a large effect size. No statistically significant differences were found on the scores of the first factor of the SRAS-R-C (To Avoid School Related Stimuli that Provoke Negative Affectivity) across gender.

\section{Correlation Coefficients between the Factors of the SRAS-R-C}

The correlation coefficients between the different factors of the SRAS-R-C and the total score of the scale were statistically significant (Table 5). With regard to the correlation coefficients between the four factors of the SRAS-R-C, the first two factors showed a statistically significant and positive correlation of high magnitude (0.53), whereas the first and third factor (0.34) and the second and third factor (0.37) showed moderate correlations. Finally, the fourth factor showed a statistically significant and positive but low correlation (0.21) with the third factor. The two first factors of the SRAS-R-C thus did not correlate with the fourth factor, as expected.

\section{Correlation Coefficients between the SRAS-R-C and the PANAS and YLOT}

Correlation coefficients of the subscales and the total score of the SRAS-R-C with the PANAS and the YLOT are in Table 6. The first three factors and the total score of the SRAS-R-C were positively correlated with negative affect and pessimism, whereas the fourth factor of the SRAS-R-C was positively correlated with positive affect and optimism. In addition, the total score of the SRAS-R$\mathrm{C}$ was inversely correlated $(-0.12)$ with the PANAS-C positive 
TABLE 4 | Latent means differences across gender and age groups in the SRAS-R-C.

\begin{tabular}{|c|c|c|c|c|}
\hline & \multicolumn{4}{|c|}{ SRAS-R-C factors } \\
\hline & $\mathbf{F I}$ & FII & FIII & FIV \\
\hline \multicolumn{5}{|l|}{ Girls (reference) } \\
\hline \multicolumn{5}{|l|}{ Boys } \\
\hline Mean estimate (ME) & 0.07 & 0.03 & 0.27 & 0.24 \\
\hline Standard error (SE) & 0.06 & 0.05 & 0.19 & 0.12 \\
\hline Critical Ratio (CR) & 1.14 & 0.59 & 1.40 & 2.08 \\
\hline \multicolumn{5}{|c|}{ 8-year-old (reference) } \\
\hline \multicolumn{5}{|c|}{ 9-year-old } \\
\hline ME & 0.07 & -0.05 & -0.23 & -0.08 \\
\hline SE & 0.08 & 0.07 & 0.16 & 0.13 \\
\hline $\mathrm{CR}$ & 0.79 & -0.72 & -1.44 & 0.62 \\
\hline \multicolumn{5}{|l|}{ 10-year-old } \\
\hline $\mathrm{ME}$ & 0.16 & -0.03 & -0.14 & 0.08 \\
\hline SE & 0.09 & 0.08 & 0.16 & 0.14 \\
\hline $\mathrm{CR}$ & 1.75 & -0.41 & -0.91 & 0.62 \\
\hline \multicolumn{5}{|l|}{ 11-year-old } \\
\hline ME & 0.15 & -0.16 & -0.76 & 1.95 \\
\hline SE & 0.09 & 0.08 & 0.19 & 0.12 \\
\hline $\mathrm{CR}$ & 1.70 & -1.99 & -3.93 & 15.77 \\
\hline \multicolumn{5}{|c|}{ 9-year-old (reference) } \\
\hline \multicolumn{5}{|c|}{ 10-year-old } \\
\hline ME & 0.08 & 0.02 & 0.10 & 0.04 \\
\hline SE & 0.07 & 0.07 & 0.15 & 0.14 \\
\hline $\mathrm{CR}$ & 1.10 & 0.21 & 0.71 & 0.27 \\
\hline \multicolumn{5}{|l|}{ 11-year-old } \\
\hline ME & 0.10 & -0.09 & -0.42 & 1.95 \\
\hline SE & 0.07 & 0.07 & 0.14 & 0.01 \\
\hline $\mathrm{CR}$ & 1.41 & -1.31 & -3.04 & 16.53 \\
\hline \multicolumn{5}{|c|}{ 10-year-old (reference) } \\
\hline \multicolumn{5}{|c|}{ 11-year-old } \\
\hline $\mathrm{ME}$ & -0.05 & -0.14 & -0.56 & 0.22 \\
\hline SE & 0.08 & 0.08 & 0.14 & 0.14 \\
\hline CR & -0.68 & -1.79 & -3.97 & 1.50 \\
\hline
\end{tabular}

FI, Negative Affectivity; Fll, Social Aversion and/or Evaluation; FIll, To Pursue Attention; FIV, To Pursue Tangible Reinforcement.

affect subscale and positively correlated (0.32) with the PANAS-C negative affect subscale. Finally, the total score of the SRAS-R$\mathrm{C}$ was positively correlated $(0.23)$ with the YLOT subscale of pessimism. No statistically significant correlation was found with respect to the YLOT subscale of optimism.

\section{DISCUSSION}

The aim of this study was to validate an instrument to assess school refusal in Spanish sample in terms of the causes that determine this behavior. At the present time, the validation of this instrument has been completed in other countries such as United Kingdom (Richards and Hadwin, 2011) and Turkey (Seçer, 2014). In this sense, the current investigation is the first study to offer the validation of the SRAS-R-C in Spanish language. The proposed model of this work, with a structure of 18 items divided into four factors, was the best-fit model with a tetrafactorial structure remaining invariant across gender and age. Latent means differences indicated that boys and 11-year-olds scored higher on the Tangible Reinforcements subscale compared with girls and their 8- and 9-year-old peers, respectively. On the contrary, for the subscales of Social Aversion and/or Evaluation and to Pursue Attention, the differences were significant and higher in younger age groups compared to 11-year-olds. The magnitude of the differences found was small in all cases except for the fourth factor. Concretely, the oldest group of students (11-year-olds) reported higher scores on the fourth factor in comparison with younger students. Appropriate indexes of reliability were obtained for the SRAS-R-C and the correlation coefficients revealed a predictable pattern between school refusal and positive/negative affect and optimism/pessimism. These results are discussed below.

Taking into consideration the different goodness-of-fit indices conducted in this study, the model proposed by Richards and Hadwin (2011) obtained the best adjustment with a three factor structure. Nonetheless, this proposal has a strong limitation because it completely removes the fourth factor. The model proposed in the present study of 18 items divided into four factors was the instrument with the best adjustment to evaluate school refusal from a broad perspective that includes the different factors that can cause this type of behavior. These results also support the four factor structure of the SRAS-R-C according to the most previous research (Kearney and Silverman, 1993; Kearney, 2006; Lyon, 2010; Haight et al., 2011; Seçer, 2014). In the own model, items 16, 17, 18, 19, and 20 were omitted. The removal of items 17 (Factor I: If you had less bad feelings (e.g., scared, nervous, sad) about school, would it be easier for you to go to school?) and 18 (Factor II: If it were easier for you to make new friends, would it be easier for you to go to school?) is in line with the findings of Seçer (2014), who argued that these items were written in conditional style and complicated the understanding of the scale. Item 19 (Factor III: Would it be easier for you to go to school if your parents went with you?) was removed from the scale because it did not

TABLE 5 | Correlations between factors and the total score of SRAS-R-C.

\begin{tabular}{|c|c|c|c|c|}
\hline SRAS-R-C factors & Total SRAS-R-C & $\mathbf{F I}$ & FII & FIII \\
\hline Fl. To Avoid School Related Stimuli that Provoke a Sense of General Negative Affectivity. & $0.70^{*}$ & & & \\
\hline Fll. To Escape from Aversive Social and/or Evaluative Situations at School. & $0.67^{*}$ & $0.53^{*}$ & & \\
\hline FIII. To Pursue Attention from Significant Others. & $0.81^{*}$ & $0.34^{*}$ & $0.37^{*}$ & \\
\hline FIV. To Pursue Tangible Reinforcement Outside the School Setting. & $0.41^{*}$ & 0.01 & -0.05 & $0.21^{*}$ \\
\hline
\end{tabular}

*Correlation is significative $p<0.001$. 


\begin{tabular}{|c|c|c|c|c|c|c|}
\hline & Factors & $\begin{array}{c}\text { FI } \\
\text { SRAS-R-C }\end{array}$ & $\begin{array}{c}\text { FII } \\
\text { SRAS-R-C }\end{array}$ & $\begin{array}{c}\text { FIII } \\
\text { SRAS-R-C }\end{array}$ & $\begin{array}{c}\text { FIV } \\
\text { SRAS-R-C }\end{array}$ & $\begin{array}{c}\text { Total } \\
\text { SRAS-R-C }\end{array}$ \\
\hline \multirow[t]{2}{*}{ PANAS-C } & Positive affect & $-0.24^{* *}$ & $-0.21^{* *}$ & n.s. & $0.18^{* *}$ & $-0.12^{* *}$ \\
\hline & Negative affect & $0.40 * *$ & $0.41^{* *}$ & $0.16^{* *}$ & n.s. & $0.32 * *$ \\
\hline \multirow[t]{2}{*}{ YLOT } & Optimism & $-0.17^{* *}$ & $-0.18^{* *}$ & n.s. & $0.19^{* *}$ & n.s. \\
\hline & Pessimism & $0.32^{* *}$ & $0.33^{* *}$ & $0.11^{* *}$ & $-0.15^{* *}$ & $0.23^{* *}$ \\
\hline
\end{tabular}

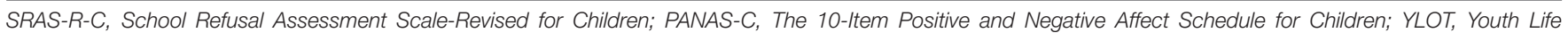
Orientation Test. ${ }^{* *} p<0.01$.

reach satisfactory performance, similar to Haight et al. (2011) and Seçer (2014). As Lyon (2010) mentioned, the hypothetical approach of these items might be confusing. Finally, items 16 (How often do you refuse to go to school because you want to have fun outside of school?), 20 [Would it be easier for you to go to school if you could do more things you like to do after school hours (e.g., being with friends)?], and 24 (Would you rather be doing fun things outside of school more than most kids your age?) were removed from Factor IV in accordance with Lyon (2010). Its removal improved model fit due to the fact that item 16 was the least specific of the scale (Lyon, 2010), whereas items 20 and 24 established a comparative with the rest of the items and their interpretation might be misinterpreted. Both items were also omitted in Kearney (2006).

The obtained results revealed reasonable indices of internal consistency, goodness-of-fit, and temporal stability for the four factors of the SRAS-R-C. Concerning the proposed classification by George and Mallery (2003), the obtained values were acceptable and more adjusted than the results obtained by more recent validations (Haight et al., 2011; Seçer, 2014). Moreover, the multigroup CFA supported the measurement and structure invariance of the scale across gender and age, so the third hypothesis was confirmed.

The present study revealed measurement and structure invariance across gender and age of the Spanish version. These results enhance the use of this version to assess latent means differences across gender and age on school refusal. Factor IV was the only one that obtained statistically significant gender differences. In this case, boys scored significantly higher than girls, which is in line with studies that indicate a greater prevalence of males in Factor IV or truancy not based on anxiety (Kearney, 2008; Kearney and Spear, 2014). Regarding age, Factors II, III, and IV presented statistically significant differences. The later age group obtained significantly higher Factor IV means with a large size magnitude in comparison with 8- and 9-yearolds. Several studies explained that high scores in this factor are more frequent during adolescence rather than childhood (Inglés et al., 2015; Kearney, 2016). In addition, these findings might be justified by the fact that this kind of school refusal is connected with truancy, which is a common problem in students of later ages (Kearney and Albano, 2004).

With respect to Factor II of the SRAS-R-C, it was not expected to obtain statistically higher means in 8-year-olds in comparison with 11-year-olds because later age students have obtained the highest scores in this factor (Kearney and Albano, 2004).
However, it is important to consider that this factor evaluates two different aspects of the same construct. On the one hand, there are items of Factor II that assess school avoidance due to reasons of social aversion, and adolescence is a time when students worry about social acceptability (Puklek et al., 2015; Thomas et al., 2015). On the other hand, the second dimension of Factor II assesses anxiety caused by academic evaluation and, in this point, 8-year-olds in Spain experience a significant increase of exigency due to the diagnostic test that is scheduled at the end of the academic year (LOMCE).

With respect to Factor III, Kearney and Albano (2004) associated this factor with pursuing attention from significant others and early school ages. Moreover, other studies highlight the relation between Factor III and separation anxiety disorder, which is more prevalent in young children (Kearney and Silverman, 1993; Higa et al., 2002; Kearney, 2002a). In this way, it might be justified that 11-year-olds obtained significantly lower scores in Factor III in comparison with the early age groups. At this point, it is important to expand empirical research about latent means differences across gender and age to contrast the obtained results with both international and national samples.

Although this study supports the four factor structure of the SRAS-R-C, the results revealed the existence of correlations between the three first factors and between Factors III and IV, which were of a high magnitude between the two first factors (0.53) and of low magnitude between Factors III and IV (0.21). These findings are in accordance with Kearney and Silverman (1993) and Higa et al. (2002). In this line, the results verify that there is no correlation between the two first factors and the fourth factor of the SRAS-R-C (Kearney and Silverman, 1993; Higa et al., 2002). This fact might be justified because the three first factors of the SRAS-R-C base school refusal on anxiety symptoms caused by the school in general (Factor I), caused by social or evaluative situations inside the school environment (Factor II), or caused by the separation of a closed person (Factor III). In contrast, Factor IV school refusal is based on obtaining tangible reinforcements outside the school setting, such as staying home playing videogames or to be with friends during school hours (Kearney, 2008).

The study of interaction between school refusal and affect, optimism, and pessimism has lacked empirical evidence. The negative affect dimension of the PANAS-C significantly and negatively correlated with the three first factors of the SRAS-R-C and the total score of the scale. Negative affect has been associated 
with feelings of sadness, fear, blame, and anger (Ebesutani et al., 2012; Pires et al., 2013), or even anxiety and depression (Watson et al., 1988; Chorpita and Daleiden, 2002; Robles and Páez, 2003; Inglés et al., 2016). Several studies have obtained positive correlations of these variables with the first three factors of the SRAS-R-C (Kearney and Silverman, 1993; Higa et al., 2002). Considering the tripartite model of anxiety, depression, and affect (Joiner et al., 1996; Sandín et al., 1999), these positive correlations were expected. These correlations provide preliminary support for the convergent and discriminant validity of the SRAS-R-C because negative affect positively correlated with the first three factors of the SRAS-R-C and the total score of the scale, whereas positive affect positively correlated with Factor IV of the SRAS-R$\mathrm{C}$, which does not justify school refusal with anxiety.

Finally, the YLOT dimension of pessimism positively and significantly correlated with the three first factors of the SRAS-R$\mathrm{C}$ and the total score of the scale. These results are supported by Gisbert-Ferrándiz et al. (2013) in a simple of 342 Spanish students of primary education, which is the only study that specifically evaluated the correlation between these variables. In their study, the positive and significant correlations between pessimism and the first three factors of the SRAS-R-C predominated, whereas Factor IV positively and significantly correlated with optimism.

\section{LIMITATIONS AND PRACTICAL IMPLICATIONS}

The current study presents certain limitations that might be solved in future investigations. On the one hand, it might be convenient to analyze variations of school refusal behavior over time with longitudinal studies, which are insufficient in current research (Kearney, 2008) and to examine the reliability and validity of the scale in higher levels of education with a wider age range of students. Moreover, to not only consider the students' perceptions, it might be interesting for future research to collect parent and teachers reports and to compare the scale in school refusing versus non-school refusing populations to assess its predictive validity. Finally, future works should evaluate in depth the relation of the SRAS-R-C with other instruments, as well as to validate the version addressed to parents and teachers as Kearney (2006) suggested. School refusal behavior should be related with other variables that would reinforce the knowledge of this construct, such as school anxiety, academic self-attributions, personality traits, and health perception.

\section{REFERENCES}

Bentler, P. M. (2005). EQS 6.1: Structural Equations Program Manual. Encino, CA: Multivariate Software, Inc.

Brandibas, G., Jeunier, B., Clanet, C., and Fouraste, R. (2004). Truancy, school refusal and anxiety. Sch. Psychol. Int. 25, 117-126. doi: 10.1177/ 0143034304036299

Brandibas, G., Jeunier, B., Gaspard, J. L., and Fouraste, R. (2001). Evaluation des modes de refus de l'ecole: validation francaise de la SRAS (School refusal
The findings of this study are useful at a pragmatic level in prevention and evaluation of this problem and in its treatment. With regard to the assessment, this work offers the first Spanish validation of the SRAS-R-C in primary education and it provides the main international instrument to specifically assess school refusal for psychology and education. In this line, early detection will be encouraged as a prevention mechanism because several studies have suggested that the progressive development of school refusal could be chronic school absenteeism or school dropout (Kearney, 2008). This is important because Spain has the highest percentage of early school dropouts (21.9\%) in comparison with the rest of countries of the European Union (Ministry of Education, Culture and Sport, 2015). Being able to identify school refusal behaviors during the early stages of education, such as primary education, would enable an early intervention and develop actions to overcome difficulties or negative ideas associated with the educational center. Additionally, the results of this study using latent means differences analysis have confirmed the complexity of this problem and that the factors of school refusal do not affect in the same measure across gender and age. Consequently, it is important to value with different attention those groups at greatest risk. This study offers a prevention tool and interesting data for intervention.

\section{AUTHOR CONTRIBUTIONS}

CG has participated conducting a literature review and writing this manuscript. CI has made substantial contributions to the conception and design of this research. He has also received the study in all its phases. CK has participated drafting the work and revising it critically for important intellectual content in all its phases. MV has participated conducting a literature review and writing this manuscript. RS has participated performing statistical analyses. JG-F has designed this research and participated performing statistical analyses.

\section{FUNDING}

Part of this research has been financed by a project of the Ministry of Economy and Competitiveness (EDU2012-35124) awarded to JG-F, by aid to contracts for training doctors [UA FPU, 2013-5795] and [UA FPU, 2015-5995] granted to CG and RS, respectively, and by aid for the recruitment of predoctorate research staff [Program VALi+d, ACIF-2014-368] granted to MV.

assessment scale) [Evaluation of school refusal modes: French validation of the SRAS (school refusal assessment scale)]. Psychol. Psychometrie 22, 45-58.

Brown, T. A. (2006). Confirmatory Factor Analysis for Applied Research. New York, NY: Guilford Press.

Byrne, B. M. (2008a). Structural Equation Modeling with EQS: Basic Concepts, Applications and Programing, 2nd Edn. New York, NY: Routledge Taylor \& Francis Group.

Byrne, B. M. (2008b). Testing for multigroup equivalence of a measuring instrument: a walk through the process. Psicothema 20, 872-882. 
Cheung, G. W., and Rensvold, R. B. (2002). Evaluating goodness-of-fit indexes for testing measurement invariance. Struct. Equ. Model. 9, 233-255. doi: 10.1207/ S15328007SEM0902_5

Chorpita, B. F., and Daleiden, E. L. (2002). Tripartite dimensions of emotion in a child clinical sample: measurement strategies and implications for clinical utility. J. Consult. Clin. Psychol. 70, 1150-1160. doi: 10.1037/0022-006X.70.5. 1150

Cohen, J. (1988). Statistical Power Analysis for the Behavioral Sciences. Hillsdale, NJ: Erlbaum.

Dembo, R., Briones-Robinson, R., Schmeidler, J., Wareham, J., Ungaro, R., Winters, K. C., et al. (2016). Brief intervention impact on truant youths' marijuana use: eighteen-month follow up. J. Child. Adolesc. Subst. Abuse 25, 18-32. doi: 10.1080/1067828X.2013.872068

Dimitrov, D. M. (2010). Testing for factorial invariance in the context of construct validation. Meas. Eval. Couns. Dev. 43, 121-149. doi: 10.1177/ 0748175610373459

Ebesutani, C., Regan, J., Smith, A., Reise, A., Higa-McMillan, C., and Chorpita, B. F. (2012). The 10-item positive and negative affect schedule for children, child and parent shortened versions: application of item response theory for more efficient assessment. J. Psychopathol. Behav. Assess. 34, 191-203. doi: 10. 1007/s10862-011-9273-2

Ey, S., Hadley, W., Allen, D. N., Palmer, S., Klosky, J., Deptula, D., et al. (2005). A new measure of children's optimism and pessimism: the youth life orientation test. J. Child Psychol. Psychiatry 46, 548-588. doi: 10.1111/j.1469-7610.2004. 00372.x

Fritz, C. O., Morris, P. E., and Richler, J. J. (2012). Effect size estimates: current use, calculations, and interpretation. J. Exp. Psychol. Gen. 141, 2-18. doi: 10.1037/ a0024338

Fujigaki, Y. (1996). The Association Between Feelings of School Avoidance and Friend Relationship Stressors - from the Standpoint of Self Image and Coping Strategies. Master's thesis. Nagoya University Graduate School of Education, Nagoya.

García-Fernández, J. M., Inglés, C. J., Gonzálvez, C., Vicent, M., Delgado, B., and Gómez-Núñez, M. I. (2016). Revisión bibliométrica del rechazo escolar: perspectivas de investigación y su análisis [Bibliometric review of school refusal: research perspectives and their analysis]. Educatio Siglo XXI 34, 71-92. doi: $10.6018 / \mathrm{j} / 252541$

George, D., and Mallery, P. (2003). SPSS for Windows Step by Step: A Simple Guide and Reference. 11.0 update, 4th Edn. Boston, MA: Allyn \& Bacon.

Gisbert-Ferrándiz, B., Vicent, J., Gisbert- Ferrándiz, A., Gonzálvez, C., and LagosSan Martín, N. (2013). "Optimismo, pesimismo y rechazo escolar [Optimism, pessimism and school refusal]," in Rechazo escolar y variables cognitivomotivacionales y de personalidad. Symposium Nacional de Psicología Clínica y de la Salud con Niños y Adolescentes, ed. J. M. García-Fernández: Elche.

Guller, L., Zapolski, T. C. B., and Smith, G. T. (2015). Personality measured in elementary school predicts middle school addictive behavior involvement. J. Psychopathol. Behav. Assess. 37, 523-532. doi: 10.1007/s10862-014-9474-6

Haight, C., Kearney, C. A., Hendron, M., and Schafer, R. (2011). Confirmatory analyses of the school refusal assessment scale- revised: replication and extension to a truancy sample. J. Psychopathol. Behav. Assess. 33, 196-204. doi: 10.1007/s10862-011-9218-9

Hambleton, R. K., and Lee, M. K. (2015). "Methods for translating and adapting tests to increase cross-language validity," in The Oxford Handbook of Child Psychological Assessment, eds D. H. Saklofske, C. R. Reynolds, and V. L. Schwean (New York, NY: Oxford University Press), 172-181.

Hendron, M., and Kearney, C. A. (2011). Bridging the gap between assessment and treatment of youths with school refusal behavior: what to do when clients ask "what now"? J. Clin. Psychol. 2, 14-21.

Higa, C. K., Daleiden, E. L., and Chorpita, B. F. (2002). Psychometric properties and clinical utility of the school refusal assessment scale in a multiethnic sample. J. Psychopathol. Behav. Assess. 24, 247-258. doi: 10.1023/A:1020727016113

Hochadel, J., Frölich, J., Wiater, A., Lehmkuhl, G., and Fricke-Oerkermann, L. (2014). Prevalence of sleep problems and relationship between sleep problems and school refusal behavior in school-aged children in children's and parents ratings. Psychopathology 47, 119-126. doi: 10.1159/000345403

Honjo, S., Sasaky, Y., Kaneko, H., Tachibana, K., Murase, S., Ishii, T., et al. (2003). Study on feelings of school avoidance, depression, and character tendencies among general junior high and high school students. Psychiatry Clin. Neurosci. 57, 464-471. doi: 10.1046/j.1440-1819.2003.01149.x

Hu, L., and Bentler, P. M. (1999). Cut-off criteria for fit indexes in covariance structure analysis: conventional criteria versus new alternatives. Struct. Equ. Modeling 6, 1-55. doi: 10.1080/10705519909540118

Inglés, C. J., García-Fernández, J. M., Vicent, M., Gonzálvez, C., and Sanmartín, R. (2016). Profiles of perfectionism and school anxiety: a review of the $2 \times 2$ model of dispositional perfectionism in child population. Front. Psychol. 7:1043. doi: 10.3389/fpsyg.2016.01403

Inglés, C. J., Gonzálvez, C., García-Fernández, J. M., Vicent, M., and MartínezMonteagudo, M. C. (2015). Current status of research on school refusal. Eur. J. Educ. Psychol. 8, 39-54.

Joiner, T. E., Catanzaro, S. J., and Laurent, J. (1996). Tripartite structure of positive and negative affect, depression, and anxiety in child and adolescent psychiatric inpatients. J. Abnorm. Psychol. 105, 401-409. doi: 10.1037/0021-843X.105.3.401

Kearney, C. A. (2002a). Identifying the function of school refusal behavior: a revision of the school refusal assessment scale. J. Psychopathol. Behav. Assess. 24, 235-245. doi: 10.1023/A:1020774932043

Kearney, C. A. (2002b). Case study of the assessment and treatment of a youth with multifunction school refusal behavior. Clin. Case Stud. 1, 67-80. doi: $10.1177 / 1534650102001001006$

Kearney, C. A. (2006). Confirmatory factor analysis of the school refusal assessment scale-revised: child and parent versions. J. Psychopathol. Behav. Assess. 28, 139-144. doi: 10.1007/s10862-005-9005-6

Kearney, C. A. (2008). School absenteeism and school refusal behavior in youth: a contemporary review. Clin. Psychol. Rev. 28, 451-471. doi: 10.1016/j.cpr.2007. 07.012

Kearney, C. A. (2016). Managing School Absenteeism at Multiple Tiers: An EvidenceBased and Practical Guide for Professionals. New York, NY: Oxford University Press.

Kearney, C. A., and Albano, A. (2004). The functional profiles of school refusal behavior: diagnostic aspects. Behav. Modif. 28, 147-161. doi: 10.1177/ 01454455033259263

Kearney, C. A., Chapman, G., and Cook, L. C. (2005). School refusal behavior in young children. Int. J. Behav. Consult. Ther. 1, 212-218. doi: 10.1037/h0100746

Kearney, C. A., and Graczyk, P. (2014). A response to intevention model to promote school attendance and decrease school absenteeism. Child Youth Care Forum 43, 1-25. doi: 10.1007/s10566-013-9222-1

Kearney, C. A., and Silverman, W. K. (1993). Measuring the function of school refusal behavior: the school refusal assessment scale. J. Clin. Child Psychol. 22, 85-96. doi: 10.1207/s15374424jccp2201_9

Kearney, C. A., and Spear, M. (2014). "School refusal behavior," in Translating Psychological Research Into Practice, eds L. Grossman and S. Walfish (Washington, DC: American Psychological Association), 83-85.

Kim, G. (2010). A validation study of the school refusal assessment scale for Korean adolescents. Korean J. Play Ther. 13, 121-139.

Liu, W., Lei, H., Li, L., Yi, J., Zhong, M., Yang, Y., et al. (2015). Factorial invariance of the mood and anxiety symptom questionnaire-short form across gender. Pers. Individ. Dif. 87, 136-140. doi: 10.1016/j.paid.2015.07.036

Lyon, A. R. (2010). Confirmatory factor analysis of the school refusal assessment scale-revised in an African American community sample. J. Psychoeduc. Assess. 28, 511-523. doi: 10.1177/0734282909353438

Maynard, B. R., Salas-Wright, C. P., Vaughn, M. G., and Peters, K. E. (2012). Who are truant youth? Examining distinctive profiles of truant youth using latent profile analysis. J. Youth Adolesc. 41, 1671-1684. doi: 10.1007/s10964012-9788-1

Mihalas, S. (2014). "School refusal behavior," in Translating Psychological Research Into Practice, eds L. Grossman and S. Walfish (Washington, DC: American Psychological Association), 85-88.

Ministry of Education, Culture and Sport (2015). Datos y Cifras. Curso Escolar 2015/2016 [Data and Numbers. School Year 2015/2016]. Madrid: Secretaría General Técnica.

Organisation for Economic Co-operation and Development (2012). PISA 2012. Programa Para la Evaluación Internacional de Los Alumnos. Informe Español. Resultados y Contexto [PISA 2012. Programme for International Assessment of Spanish Students: Results and Context], Vol. 1. Madrid: Ministerio de Educación, Cultura y Deporte. 
Pina, A. A., Zerr, A. A., Gonzales, N. A., and Ortiz, C. D. (2009). Psychosocial interventions for school refusal behavior in children and adolescents. Child Dev. Perspect. 3, 11-20. doi: 10.1111/j.1750-8606.2008.00070.x

Pires, P., Figueiras, A., Ribas, R., and Santana, C. (2013). Positive and negative affect schedule: psychometric properties for the Brazilian Portuguese version. Span. J. Psychol. 16, 1-9. doi: 10.1017/sjp.2013.60

Puklek, M., Inglés, C. J., Marzo, J. C., and García-Fernández, J. M. (2015). School anxiety inventory: reliability and validity evidence in a sample of Slovenian adolescents. Psychol. Sch. 52, 860-873. doi: 10.1002/pits. 21862

Richards, H. J., and Hadwin, J. A. (2011). An exploration of the relationship between trait anxiety and school attendance in young people. School Ment. Health 3, 236-244. doi: 10.1007/s12310-011-9054-9

Robles, R., and Páez, F. (2003). Estudio sobre la traducción al español y las propiedades psicométricas de las escalas de afecto positivo y negativo (PANAS) [Study on Spanish translation and psychometric properties of the scales of positive and negative affect (PANAS)]. Salud Ment. 26, 69-75.

Samuel, D. B., South, S. C., and Griffin, S. A. (2015). Factorial invariance of the five-factor model rating form across gender. Assessment 22, 65-75. doi: 10.1177/ 1073191114536772

Sandín, B., Chorot, P., Lostao, L., Joiner, T. E., Santed, M. E., and Valiente, R. M. (1999). Escalas PANAS de afecto positivo y negativo: validación factorial y convergencia transcultural [The PANAS scales of positive and negative affect: factor analytic validation and cross-cultural convergence]. Psicothema 11, 37-51.

Seçer, I. (2014). The adaptation of school refusal assessment scale into Turkish: reliability and validity studies. Pakistan J. Stat. 30, 1197-1202.

Thomas, S. A., Weeks, J. W., Dougherty, L. R., Lipton, M. F., Daruwala, S. E., Kline, K., et al. (2015). Allelic variation of risk for anxiety symptoms moderates the relation between adolescent safety behaviors and social anxiety symptoms. J. Psychopathol. Behav. Assess. 37, 645-662. doi: 10.1007/s10862-015-9483-0
Thornton, M., Darmody, M., and McCoy, S. (2013). Persistent absenteeism among Irish primary school pupils. Educ. Rev. 65, 488-501. doi: 10.1080/00131911. 2013.768599

Thrul, J., Pabst, A., and Kraus, L. (2016). The impact of school nonresponse on subtance use prevalence estimates-Germany as a case study. Int. J. Drug Policy 27, 164-172. doi: 10.1016/j.drugpo.2015.06.005

Tsaousis, I., and Kazi, S. (2013). Factorial invariance and latent mean differences of scores on trait emotional intelligence across gender and age. Pers. Individ. Dif. 54, 169-173. doi: 10.1016/j.paid.2012.08.016

Watanabe, Y., and Koishi, H. (2000). A study on the negative feelings toward school in junior high school students. Bull. Fac. Hum. Dev. 8, 1-12.

Watson, D., Clark, L. A., and Carey, G. (1988). Positive and negative affectivity and their relation to anxiety and depressive disorders. J. Abnorm. Psychol. 97, 346-353. doi: 10.1037/0021-843X.97.3.346

Yahaya, A., Ramli, J., Hashim, S., Ibrahim, M. A., Kadir, H. B. H., Boon, Y., et al. (2010). The effects of various modes of absenteeism problem in school on the academic performance of students in secondary schools. Eur. J. Soc. Sci. 12, 624-639.

Conflict of Interest Statement: The authors declare that the research was conducted in the absence of any commercial or financial relationships that could be construed as a potential conflict of interest.

Copyright (c) 2016 Gonzálvez, Inglés, Kearney, Vicent, Sanmartín and GarcíaFernández. This is an open-access article distributed under the terms of the Creative Commons Attribution License (CC BY). The use, distribution or reproduction in other forums is permitted, provided the original author(s) or licensor are credited and that the original publication in this journal is cited, in accordance with accepted academic practice. No use, distribution or reproduction is permitted which does not comply with these terms. 